\title{
COMPARISON OF CONTEXT-BASED LEARNING AND TRADITIONAL METHOD IN COGNITIVE AND PSYCHOMOTOR DOMAINS AND CRITICAL THINKING OF UNDERGRADUATE NURSING STUDENTS
}

\author{
${ }^{1}$ School of Allied Medical Sciences, Shahrekord University of Medical Sciences, Shahrekord, Iran
}

\begin{abstract}
BACKGROUND. Today, due to advances in science, students must learn to be more active. Active learning will enhance students' learning and motivation. The purpose of this study was to compare the two methods of Context-Based Learning (CBL) and traditional method in cognitive and psychomotor domains and critical thinking of undergraduate nursing students.

METHODS. This was a semi-experimental study. The participants were 50 (25 CBL and 25 traditional) senior nursing students spending internship training period in the neurology ward. Data collection tool was a four-section questionnaire. After passing the period, the students were asked to complete the questionnaire once more to determine modification degree in each category of cognitive, psychomotor and affective domain, learning process and critical thinking of student after applying CBL and traditional methods. Subsequent to the completion of the questionnaire, prior and next data were compared. Data were analyzed by SPSS software and the significance level considered 5\%. T-test and paired T-test as well as Mann-Whitney test were used to compare the attributes of independent and dependent variables.

RESULTS. Results of the study showed that in CBL group, the scores were increased in all five behavioral domains after the intervention. However, in the traditional group, the difference of score mean of the students' behavior was not significant before and after the intervention. In addition, the results indicated that in CBL group, learning score increased in level of knowledge, understanding, application, analysis, and synthesis and evaluation. In the traditional group, while learning score increased in knowledge and understanding domains, it not only did not increase in application, analysis, synthesis and evaluation levels but it was also lower than in the CBL group.

CONCLUSIONS. In CBL group, behavioral score increased in terms of respect, self-awareness and selfevaluation, communication skills, accountability, critical thinking as well as motivation, and in learning process in levels of knowledge, understanding, application, analysis, syntheses and evaluation. New educational methods lead to learn more deeply and become more sustainable.
\end{abstract}

Keywords: cognitive-behavioral, learning method, critical thinking

\section{INTRODUCTION}

Nursing is considered to be a complex, challenging and effective profession in the three areas: prevention, treatment and rehabilitation (1). Universities seek appropriate teaching methods to promote competence, clinical decision-making, continuous and active learning of students. Traditional methods do not focus sufficiently on understanding the concepts and applying them. The lack of student involvement in the learning process leads to a lack of innovation and the right mindset to meet the needs of the patient. In the field of nursing, there is always a gap between theoretical training and practice where learners are often not able to apply theory to practice (2-4). Moreover, in the process of learning, the cognitive domain is more important than the affective and psychological domains (5), and in the cognitive domain, knowledge and levels of understanding are taken into account more while the levels of analysis, synthesis and evaluation levels have not been applied. Today, fostering critical thinking is compulsory at all levels of education $(5,6)$. Critical thinking is summarized in five skills that include stating the problem, selecting sufficient data to solve the problem, identifying relevant and inappropriate hypotheses, and modifying and selecting relevant hypotheses (5). In addition, the teaching of communication skills, 
responsibility, respect, self-awareness and judgmental competence are seen as significant indicators of the importance of adapting learning behavior in modern teaching methods (3).

The teaching methods can be divided into teachercentered or direct teaching methods and indirect or learner-centered teaching methods (5). Lecture method is an instructional strategy that applies when more students are engaged in learning and less time and budget is available (7).

Indirect teaching methods are rooted in constructivism in psychology (5). Constructivists believe that knowledge is basically personal and is acquired by the individual through exploring and searching (8). Moreover, they considered that humans can learn a new and unknown concept by their previous knowledge which is kept in their mind and acquired by their actual experiences $(5,9)$. Learnercentered teaching methods do not view the learning process as linear but view it as an integrated and complex process that leads to the creation of positive and effective mental tasks in students. An effective nurse needs some ability to deal with real-life issues in the clinic (2).

Today, the promotion of critical thinking has been recognized by the Council of Europe as teaching excellence in nursing education. There is consensus on the importance of critical thinking $(4,10)$.

CBL (Context-Based Learning) can be considered as one of the types of problem-based learning (PBL) and is an effective strategy in teaching nursing students. There are a number of teaching strategies that consider CBL to be very important. CBL offers skilled operation in a rapidly changing care environment and is reaching out to the international community (11).

Research articles in Iran, particularly in the field of nursing, have looked at the cognitive domain in general or in specific assessments, focusing on the level of knowledge and less on the level of understanding including application, analysis, synthesis and evaluation. In addition, most of the studies have investigated the effect of learning from teaching methods on students' behavior using problem-solving and lecture methods. CBL can result not only in prompting learning capacity, continuous and selfcentered learning, but it can also lead students to focus on understanding concepts, innovating, and acquiring social skills. In terms of teaching conditions, in response to the motivational needs of nursing majors, and the need for the innovation creation and development of teaching that moves toward active learning, the present study was done to compare context-based learning and traditional method in the cognitive and psychomotor domain and critical thinking of undergraduate nursing students in Shahrekord University of Medical Sciences in Southwest of Iran.

\section{MATERIALS AND METHODS}

This was a semi-experimental study. Multi-stage random sampling method was adopted. Fifty senior nursing students who have passed the training period in the neurology ward were divided into 8 blocks, numbered from 1 to 8 , and each number was recorded on a similar small card. After that, all the cards were put in a box, and one card was drawn randomly after shaking. Even numbers were considered as CBL group and odd numbers as traditional group. Based on previous research and using sample size calculation formulas, the number of participants in each group was determined at 24 students $(\mathrm{d}=0.14, \mathrm{p}=0.5$ and $q=0.5$ ). These groups had not experimented with this teaching method. To allow the students to participate in the research, they were informed of the purpose of the research and asked to fill out a consent form. They were also assured that all research data is confidential and used for research purposes only.

Ethics approval (code 12-3-92) was obtained from Shahrekord University of Health Sciences. The study was registered at the Clinical Research Center of the Ministry of Health under the code IRCT2013070313768N4. The data collection tool was a questionnaire composed of four parts: the first part: demographic characteristics; the second part: the standard questionnaire assessing student behavior with several sections including: "respect" with 10 questions, "responsibility" with 16 questions, "communication skills" with 11 questions, "selfawareness and self-evaluation" with 8 questions as well as "critical thinking" with 9 questions. The third part was a standard questionnaire on student attitudes which included several sections such as "the role of the pupils" with 10 questions, "the role of the teachers" with 13 questions and "effectiveness of the ward in student's viewpoint" with 11 questions. The fourth part was a questionnaire established by the researcher on the learning rate of the students of the two groups evaluated in terms of knowledge, comprehension, application, analysis, synthesis as well as the level of evaluation. Validity of the questionnaires Critical Thinking Disposition was confirmed by content validity and the reliability was 0.8 via Alpha Cronbach (12).

Before using the two methods, first, the learning objective was defined, then the essential concepts related to the topic of the lesson were recognized. In the CBL method, the steps were carried out as follows: the first step: check the status. During this period, some basic functional conditions of nursing in the 
form of written scripts were explained to the students. These conditions were associated with four diseases including stroke, multiple sclerosis, myasthenia gravis and Guillain-Barre disease. Students were encouraged to explore the condition with an emphasis on the nurse's role in the condition, the applicant's commitment, and the state of health. During this step, trainees should determine what they know based on previous experiences, what they don't know, and what they need to learn to be a nurse in this situation. Williams calls these stages the "self-regulatory" stages which are important elements of metacognition (11).

The second step: self-directed research. During this step, learners set goals for themselves and look for reliable sources of information that could be useful. In this step, students researched or got advice from resources or people. At the end of this period, students asked a few questions in the form "Why?", "What?" and "What will happen?" This process helped learners develop deep thinking skills in the form of self-directed learning, which is important to the learning process. In this study, students followed the same mentioned process (11).

Step Three: Integration of new information. At this point, students incorporated new information acquired in the context of the disease. In other words, they actually merged new and old concepts. In this process, students must apply what they had learned under similar conditions. At this point, the instructor asked questions about certain scenarios to assess the learner against the four scenarios (11).

Fourth step: deep thinking (reaction). In the final stage, the students discussed their learning resources
At the end of the training period, the participants were asked to re-fill the questionnaires to determine the extent of change in different levels of the cognitive, learning and critical thinking domains after completing the training period and applying CBL or traditional methods. After completing the questionnaire, the before and after data were compared. In addition, to determine the level of student learning, scores obtained from this lesson before and after training were compared in both the CBL group and the traditional group.

Data were analyzed using SPSS software and the significance level was considered as 5\% for all data. T-test and Paired T-test, as well as Mann-Whitney test, were used to compare the characteristics of independent and dependent variables in the two groups.

\section{RESULTS}

The average age of the participants in both CBL and traditional groups was between 20 and 25 years. In CBL and traditional groups, $85 \%$ and $80 \%$ of the participants were female, respectively. In both the CBL and traditional groups, $60 \%$ of the participants were interested in nursing. There was no significant difference between two groups on age, sex, interest in nursing and the family economy. The average rating of the CBL group increased in all five behavioral domain (respect, accountability, communication skills, selfawareness and self-evaluation, critical thinking) after the intervention $(\mathrm{P}<0.05)$, while in control group, the mean score of the students' behavior was not significant before and after the intervention.

Table I. Mean score of the student's learning in CBL and traditional groups before and after the intervention

\begin{tabular}{|c|c|c|c|c|c|c|}
\hline Groups & $\begin{array}{c}\text { Before } \\
\text { (CBL group) }\end{array}$ & $\begin{array}{c}\text { After } \\
\text { (CBL group) }\end{array}$ & $P$ & $\begin{array}{c}\text { Before } \\
\text { (traditional } \\
\text { group }\end{array}$ & $\begin{array}{c}\text { After } \\
\text { (traditional } \\
\text { group) }\end{array}$ & $P$ \\
\hline Knowledge & 8 & 14 & $\mathrm{P}<0.05$ & 7.5 & 13 & $\mathrm{P}<0.05$ \\
\hline Understanding & 7 & 15 & $\mathrm{P}<0.05$ & 7.75 & 14.5 & $\mathrm{P}<0.05$ \\
\hline Application & 6 & 15 & $\mathrm{P}<0.05$ & 7.25 & 7 & $\mathrm{p}>0.05$ \\
\hline Analysis & 9 & 14.25 & $\mathrm{P}<0.05$ & 9.8 & 9.3 & $\mathrm{p}>0.05$ \\
\hline Combination & 8 & 12 & $\mathrm{P}<0.05$ & 7 & 7 & $\mathrm{p}>0.05$ \\
\hline Evaluation & 6.5 & 13 & $\mathrm{P}<0.05$ & 7.25 & 7.5 & $\mathrm{p}>0.05$ \\
\hline
\end{tabular}

and researched methods with their classmates. During the process, students realized what they should and should not do in order to achieve better results and use the reaction under future conditions. During this phase, learners and instructors provided an important structure regarding their participation in the learning process (11).

In the traditional group, students were taught based on the teacher-centered training method as in the past.
The results of the study showed that the mean score of learning after the intervention increased in both CBL and traditional groups; also, there was a significant relationship between learning scores before and after the research in both groups (Table I). However, in the CBL group, learning score increased in knowledge, understanding, application, analysis, synthesis and evaluation levels; in the traditional group, while the learning score increased in knowledge and 
understanding domains, it not only did not increase in application, analysis, synthesis and evaluation levels, but it was also lower than in the CBL group.

In addition, the mean score of the students' attitude and critical thinking increased in the CBL group after the intervention $(\mathrm{p}<0.05)$. However, there was no significant difference between the mean score of the students' attitude and critical thinking before and after the intervention in the control group.

\section{DISCUSSION}

Respect was one of the evaluation criteria to evaluate student behavior before and after using both methods. William and Day in their research stated that the information and experiences gained from the CBL approach instil trust and respect between instructor and student (11). Hunt et al.'s results suggest that appropriate social interactions with classmates and respect among them are among the most important outcomes of teamwork (13). In this study and according to research performed by Dehkordi et al. (3), the obtained mean score of the student respect has increased significantly in CBL and collaborative methods after the intervention, the increase in CBL method was more than collaborative one. However, in the traditional method, the score of respect before and after the intervention was not significantly different.

In the present study, the criteria for respect were: listening to others, acknowledging the help and contributions of others, not interrupting others in conversation, apologizing for the delay, considering the value of information separated from the value of its provider, etc. Therefore, teachers need to keep in mind that one of the effective factors in encouraging learning and changing students behavior is respecting them. Another criterion for assessing students' behavior is communication skills. The results of Sandars et al. indicated that one of the collaborative learning facilitators is the feeling of belonging and love (14). In the study by Haunt et al, one of the major outcomes of collaborative learning teamwork is to increase student involvement in classroom activities and promotion of their communication skills (15). The results of the study Trimer et al. showed that the CBL method increased the sense of teamworking in the students. In this method, communication occurs in a way that people considered as a resource (16). In the present study, the mean score of the communication skills section increased after the CBL intervention. Teachers should pay more attention to this key point as better communication skills among students, teachers, educational staff and patients will increase students' self-satisfaction and self-confidence.
Another aspect of student behavior assessment was self-awareness and self-evaluation. The most important barrier to the implementation of the $\mathrm{CBL}$ method was the difficulty in changing the teaching method from a content-oriented process to a studentoriented process by the instructors (17). This method emphasizes the independent student role in learning and evaluation. In previous studies, students stated: "We found our strengths in the CBL method and our self-confidence increased" (18). In the current study, the mean self-evaluation score in CBL increased after the intervention. The students' self-assessment will provide the best way to find out their strengths and weaknesses and to criticize themselves fairly; because when students are evaluated by others, they may resist and reject those comments. In this paper, accountability was one of the aspects of evaluating students' behavior. The results from previous studies have shown that about $68 \%$ of students accepted responsibility and collaboration around the patients' bed in hospitals. Approximately $80 \%$ of the students considered the CBL method as a proper factor for more familiarity with the clinical environment. They expressed: "CBL method led to the promotion of clinical performance in mental health services $(3,4,19)$. In our study, the mean scores of accountability aspect in CBL method increased after the intervention.

The mean critical thinking score was improved after the CBL intervention, but in the traditional method, there was no significant relationship between the mean critical thinking score before and after the intervention. The results of this study are similar to Dehkordi's findings that showed PBL education increases students' critical thinking skills (4). The students who learned to use problem-solving methods scored significantly better on critical thinking skills than students who learned the traditional method (20). The findings of the study by Williams and Day show that CBL increases students critical thinking skills and emotional sympathy in clinical settings (11).

In the present study, critical thinking skills were measured by several factors including selection of the main and key aspects to facilitate discussion, use of decision-making process, creativity and innovation, appropriate use of resources, proper feedback, the ability to ask the relative questions and strong concluding. The most important outcome of collaborative teaching methods is the individual involvement of all students in learning and caring for patients. Because the individual is responsible for patients care and tries to promote her/his capabilities. Besides, the students criticize their performance regularly and try to do their best.

In addition, the results of the study indicated that the CBL method led to a change in the attitude of 
the students but traditional methods did not change students' attitude. Choi et al. announced that students who learned problem solving methods were more motivated than students who learned traditional methods (20). The increase of students motivation would change their attitude to teaching-learning process. The findings of Sandars et al. showed that one of the facilitating factors of the learning through the CBL method is accepting the approach by the learners (14).

The result of the study demonstrated that the students' learning scores increased after using the CBL and traditional methods. But, in CBL method, the learning scores increased at the level of knowledge, understanding, application, analysis, synthesis and evaluation, while in traditional method it increased only in knowledge and understanding categories. Moreover the learning scores not only did not increase in application, analysis, synthesis and evaluation, but were also lower than in the CBL method (11). Tiwari declared that the students who studied problem solving methods scored higher than students who studied traditional method; and the higher scores were maintained for two years after using the PBL method (6). Consequently, when students are actively involved in learning process, they will be eager to learn and strive for more up-to-date information by researching new sources.

\section{CONCLUSION}

According to the results of the study, we suggest that new teaching methods can be used in teaching the theory and practice of nursing, medical and paramedical courses.

\section{Financial support and sponsorship}

Hereby, the authors thank the respectful students for participating in this study and Research and Technology Deputy of Shahrekord University of Medical Sciences for funding this research project.

\section{Conflicts of interest}

There are no conflicts of interest.

\section{REFERENCES}

1. Bramhall E. Effective communication skills in nursing practice. Nurs Stand. 2014;29(14):53. https://doi.org/10.7748/ns.29.14.53.e9355

2. Yasbolaghi Sharahi B, Zare M, Sarikhani R. Effects of the Bybee (5E) teaching method on learning and Retention in the Basic Concepts of Nursing. J Nurs Educ. 2016;5(1):30-7.
3. Dehkordi AH, Heydarnejad MS. The impact of problem based learning and lecturing on the behaviour and attitudes of Iranian nursing students. Dan Med Bull. 2008;55(4):224-6.

4. Dehkordi AH, Heydarnejad MS. The effects of problem-based learning and lecturing on the development of Iranian nursing students' critical thinking. Pak J Med Sci. 2008;24(5):740-43.

5. Latifi M, Shaban M, Nikbakht Nasrabadi A, Mehran A, Parsa Yekta Z. Effect of clinical evaluation with portfolio on critical thinking skills of nursing students. Iran J Med Sci. 2011;11(4):36881.

6. Tiwari A, Lai P, So M, Yuen K. A comparison of the effects of problem-based learning and lecturing on the development of students' critical thinking. Med Educ. 2006;40(6):547-54. https:// doi.org/10.1111/j.1365-2929.2006.02481.x

7. İlgüy $\mathrm{M}$, İlgüy $\mathrm{D}$, Fişekçioğlu $\mathrm{E}$, et al. Comparison of case-based and lecture-based learning in dental education using the SOLO Taxonomy. J Dent Educ. 2014;78(11):1521-7. https://doi/10.1002 j.0022-0337.2014.78.11.tb05827.x

8. Huang H-M, Rauch U, Liaw S-S. Investigating learners' attitudes toward virtual reality learning environments: Based on a constructivist approach. Comput Educ. 2010;55(3):1171-82. https://doi. org/10.1016/j.compedu.2010.05.014

9. Kala S, Isaramalai S-a, Pohthong A. Electronic learning and constructivism: A model for nursing education. Nurse Educ Today. 2010;30(1):61-6. https://doi.org/10.1016/j.nedt.2009.06.002

10. Wilkinson JM. Nursing process and critical thinking: Pearson Higher Ed; 2011.

11. Williams B, Day RA. Context based learning Philadelphia: Lippincott; 2006.

12. Gupta K, Iranfar S, Iranfar K, et al. Validly and reliability of California critical thinking disposition inventory (CCTDI) in Kermanshah University of Medical Sciences. Educ Res Med Sci. 2012;1(1).

13. Kuh GD, Kinzie J, Schuh JH, Whitt EJ. Student success in college: Creating conditions that matter: John Wiley \& Sons; 2011.

14. Sandars J, Langlois M, Waterman H. Online collaborative learning for healthcare continuing professional development: a cross-case analysis of three case studies. Med Teach. 2007;29(1):e9-e17. https://doi.org/10.1080/01421590601045916

15. Hunt P, Soto G, Maier J, Müller E, Goetz L. Collaborative teaming to support students with augmentative and alternative communication needs in general education classrooms. Augment Altern Comm. 2002;18(1):20-35. https://doi. org/10.1080/aac.18.1.20.35

16. Kaddoura MA. Critical thinking skills of nursing students in lecture-based teaching and case- 
based learning. Learning. 2011;5(2):20. https://doi. org/10.20429/ijsotl.2011.050220

17. Barnett T, Cross M, Shahwan-Akl L, Jacob E. The evaluation of a successful collaborative education model to expand student clinical placements. Nurse Educ Pract. 2010;10(1):17-21. https://doi. org/10.1016/j.nepr.2009.01.018

18. Barker D, Quennerstedt M, Annerstedt C. Interstudent interactions and student learning in health and physical education: A post-Vygotskian analysis. Phys Educ Sport Peda. 2013;20(4):409426. https://doi.org/10.1080/17408989.2013.868875

19. Nair SP, Shah T, Seth S, et al. Case based learning: a method for better understanding of biochemistry in medical students. J Clin Diagnostic Res: JCDR. 2013;7(8):1576. https://doi.org/10.7860/ JCDR/2013/5795.3212
20. Choi E, Lindquist R, Song Y. Effects of problembased learning vs. traditional lecture on Korean nursing students' critical thinking, problemsolving, and self-directed learning. Nurse Educ Today. 2014;34(1):52-6. https://doi.org/10.1016/j. nedt.2013.02.012

\section{Received: 21.05.2021}

Accepted for publication: 25.10.2021

\section{Address for correspondence:}

Ali Hasanpour-Dehkordi

School of Allied Medical Sciences,

Shahrekord University of Medical Sciences

Shahrekord, Iran

E-mail: alihassanpourdehkordi@gmail.com 